\title{
Simon Brelaud, Françoise Briquel-Chatonnet. "Quelques réflexions sur la désignation des chrétiens dans l'inscription du mage Kirdīr et dans l'empire sassanide »
}

\section{Christelle Jullien}

\section{OpenEdition}

\section{Journals}

Édition électronique

URL : http://journals.openedition.org/abstractairanica/50909

DOI : $10.4000 /$ abstractairanica. 50909

ISBN : 1961-960X

ISSN : 1961-960X

Éditeur :

CNRS (UMR 7528 Mondes iraniens et indiens), Éditions de l'IFRI

\section{Référence électronique}

Christelle Jullien, «Simon Brelaud, Françoise Briquel-Chatonnet. « Quelques réflexions sur la désignation des chrétiens dans l'inscription du mage Kirdir et dans l'empire sassanide » ", Abstracta Iranica [En ligne], Volume 40-41 | 2019, document 9, mis en ligne le 30 décembre 2019, consulté le 21 avril 2021. URL : http://journals.openedition.org/abstractairanica/50909; DOI : https://doi.org/ 10.4000/abstractairanica.50909

Ce document a été généré automatiquement le 21 avril 2021

Tous droits réservés 


\title{
Simon Brelaud, Françoise Briquel- Chatonnet. "Quelques réflexions sur la désignation des chrétiens dans l'inscription du mage Kirdīr et dans l'empire sassanide »
}

\author{
Christelle Jullien
}

\section{RÉFÉRENCE}

Simon Brelaud, Françoise Briquel-Chatonnet. « Quelques réflexions sur la désignation des chrétiens dans l'inscription du mage Kirdīr et dans l'empire sassanide », Parole de l'Orient 43, 2017, p. 113-136

À partir d'une vaste documentation qui avait primitivement été réunie par C. Jullien et F. Jullien dans une analyse historique et littéraire publiée en 2002 (Numen 49, p. 282-335), les AA. reviennent sur le dossier de la désignation des chrétiens dans l'inscription du mage Kirdīr et postérieurement dans l'empire sassanide. Le matériau de l'enquête prospective de 2002 est intégralement repris dans une optique quelque peu différente sur certains points. Leur interprétation est que la distinction terminologique entre kristyānēe et nașrāyē se figea à la faveur des persécutions du règne de Šābuhr II ; les naşrāyē désigneraient selon leur lecture des chrétiens dont les pratiques ne correspondaient plus à celles de l'Église alors en cours de structuration. Les autorités sassanides auraient utilisé ce terme "consciemment » " en vue d'humilier l'Église des kristyānē » en l'étendant à tous les chrétiens de l'empire perse. D'après cette hypothèse, les mazdéens auraient ainsi opéré une différenciation entre des groupes chrétiens ou christianisants en fonction de questions doctrinales proprement chrétiennes. Cela supposerait une connaissance subtile des controverses internes à la communauté par les autorités mazdéennes, et ce dès l'époque de Kirdīr au III ${ }^{\mathrm{e}}$ siècle. Par ailleurs, l'idée 
qu'on ne «trouve de traces du terme nașrāyē que dans les récits des martyrs qui sont composés à la même époque » (i.e. au moment où l'Église d'Orient se réorganise, à partir du début $d u V^{e} s$.) est délicate car la question des dates de rédaction des différents actes de martyrs sous Šābuhr II est assez complexe ; la plupart comporte des éléments liés à des contextes largement postérieurs au IV et même au début du $V^{e} s$. Voir la réflexion de K. Smith dans The Martyrdom and History of Blessed Simeon bar Sabba e, (Persian Martyr Acts in Syriac: Text and Translation 3), Piscataway, 2014, p. xx-xxiv (et il rappelle ailleurs avec acuité comment le christianisme a pu être considéré par les autorités civiles et religieuses perses comme un élément de «non-iranité » au sein de l'empire). L'histoire de Mār Kirdag est à ce propos évocatrice puisque le cadre de la narration donne 358 comme date du martyre pour une rédaction évaluée par J. Walker au VI ${ }^{e}$ s. (éd. 2006) dans un contexte polico-religieux et une situation communautaire bien différents. Les études réalisées dans le cadre du programme Persian Martyr Acts in Syriac sous la direction d'A. Becker mettent progressivement à disposition de la communauté scientifique les matériaux de ce corpus. Pour la période de Šābuhr II, voir par ex. l'étude de K. Smith et J. Saint-Laurent sur les actes de Behnam et Sarah rédigés tardivement, au moment de la fondation du sanctuaire (terminus ante quem XII ${ }^{\mathrm{e}}$ siècle); sur la discussion de la date de la mise par écrit de l'histoire de Siméon, voir dernièrement K. T. van Bladel qui avance des arguments en faveur du VI ${ }^{\mathrm{e}} \mathrm{s}$. (2017).

\section{AUTEURS}

\section{CHRISTELLE JULLIEN}

CNRS, Mondes iranien et indien, Paris 